\title{
Clearing the surgical backlog caused by COVID-19 in Ontario: a time series modelling study
}

\author{
Jonathan Wang MASc, Saba Vahid PhD, Maria Eberg MSc, Shannon Milroy MSc, John Milkovich, \\ Frances C. Wright MD MEd, Amber Hunter MBA, Ryan Kalladeen HBA, Claudia Zanchetta RN MN(ACNP), \\ Harindra C. Wijeysundera MD PhD, Jonathan Irish MD MSC
}

Cite as: CMAJ 2020 November 2;192:E1347-56. doi: 10.1503/cmaj.201521; early-released September1, 2020

\begin{abstract}
BACKGROUND: To mitigate the effects of coronavirus disease 2019 (COVID-19), jurisdictions worldwide ramped down nonemergent surgeries, creating a global surgical backlog. We sought to estimate the size of the nonemergent surgical backlog during COVID-19 in Ontario, Canada, and the time and resources required to clear the backlog.
\end{abstract}

METHODS: We used 6 Ontario or Canadian population administrative sources to obtain data covering part or all of the period between Jan. 1, 2017, and June 13,2020 , on historical volumes and operating room throughput distributions by surgery type and region, and lengths of stay in ward and intensive care unit (ICU) beds. We used time series forecasting, queuing models and probabilistic sensitivity analysis to estimate the size of the backlog and clearance time for a $+10 \%$ ( +1 day per week at $50 \%$ capacity) surge scenario.

RESULTS: Between Mar. 15 and June 13, 2020, the estimated backlog in Ontario was 148364 surgeries (95\% prediction interval 124508-174589), an average weekly increase of 11413 surgeries. Estimated backlog clearance time is 84 weeks (95\% confidence interval [Cl] 46-145), with an estimated weekly throughput of 717 patients (95\% Cl 326-1367) requiring 719 operating room hours $(95 \% \mathrm{Cl}$ 431-1038), 265 ward beds (95\% Cl 87-678) and 9 ICU beds ( $95 \% \mathrm{Cl} 4-20)$ per week.

INTERPRETATION: The magnitude of the surgical backlog from COVID-19 raises serious implications for the recovery phase in Ontario. Our framework for modelling surgical backlog recovery can be adapted to other jurisdictions, using local data to assist with planning.

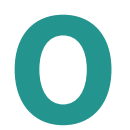

n Mar. 11, 2020, the World Health Organization (WHO) declared a global pandemic of coronavirus disease 2019 (COVID-19), which has exacted a massive global impact on health, politics and the economy. ${ }^{1}$ With some jurisdictions past the peak of the first wave, the strain on the health care system is becoming apparent - specifically, the impact on surgical care. $^{2}$ The CovidSurg Collaborative estimated that 28404603 surgeries would be cancelled or postponed across 190 countries in the initial 12 weeks of COVID-19, including $37.7 \%$ of cancer surgeries and $81.7 \%$ of other (benign) surgeries. ${ }^{3}$ If countries increased normal surgical volume by $20 \%$, it would take a median of 45 weeks to clear the backlog. Modelling postpandemic recovery for elective orthopedic surgery in the United States suggested it would take 7-16 months to reach a steady state with a backlog of more than 1 million surgeries. ${ }^{4}$

On Mar. 15, 2020, Ontario's Ministry of Health directed hospitals to begin a measured "ramping down of elective surgeries and other nonemergent clinical activity" in anticipation of a COVID-19 surge. ${ }^{5}$ On May 26, 2020, the Ministry of Health lifted the directive, allowing hospitals to gradually increase elective and time-sensitive surgeries. ${ }^{6}$ The reduction in nonemergent surgeries in Ontario because of COVID-19 has created a substantial surgical backlog. Our objective was to estimate the size of the nonemergent surgical backlog owing to COVID-19 in Ontario, and the time and resources required to clear this backlog.

\section{Methods}

The framework for developing these estimates is outlined in Figure 1. At the recommendation of our regional and hospital partners for feasible surge scenarios, we considered a $+10 \%$ ( $1 \mathrm{~d}$ per week at $50 \%$ capacity) surge scenario, adding 8 hours per day incremental to a 5-day operating week. We included surgeries performed in a fully equipped operating room and categorized 


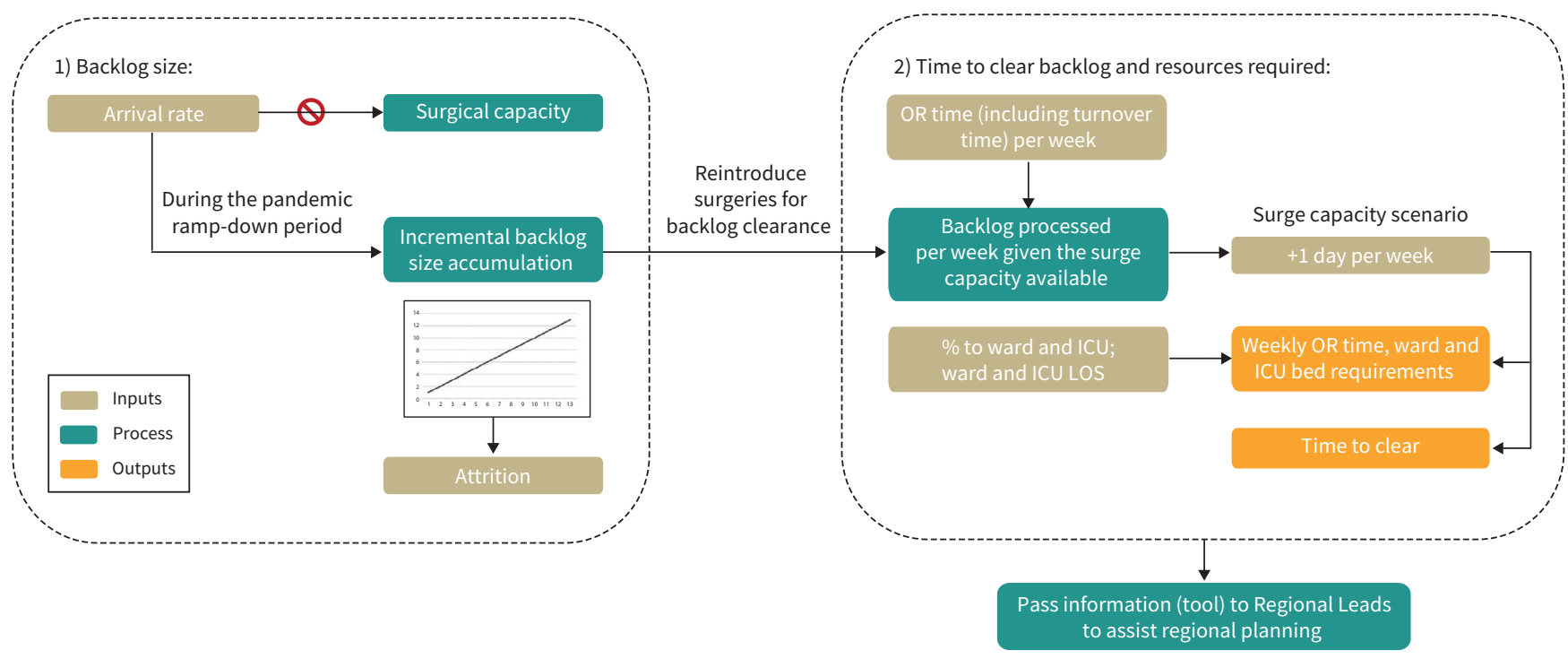

Figure 1: Schematic of the approach to model the surgical backlog. Note: ICU = intensive care unit, LOS = length of stay, OR=operating room.

them as cancer, cardiac (coronary artery bypass graft and valve procedures), vascular, transplant, pediatric and other surgeries (general, orthopedic, gynecologic, urologic, ophthalmic, etc.). A full breakdown of the procedure types included for pediatric, cancer and other surgeries is provided in Appendix 1 (available at www.cmaj.ca/lookup/doi/10.1503/cmaj.201521/tab-related -content). For cancer, vascular, pediatric and other surgeries, nonemergent surgeries are grouped by patient priority level (P2, $\mathrm{P} 3$ and P4). ${ }^{7}$ Time-sensitive surgeries are categorized as cancer P2-P4, cardiac, transplant and vascular P2-P3.

\section{Data sources}

We used 6 administrative data sources to parameterize our model: the Province of Ontario Wait Times Information System, Canadian Institute for Health Information National Ambulatory Care Reporting System, Canadian Institute for Health Information Discharge Abstract Database, CorHealth Ontario Cardiac Registry, Trillium Gift of Life Network Organ and Tissue Allocation System and the Surgery Efficiency Target Program. Full descriptions of the Ontario-specific data sets can be found in Appendix 1. We used the Discharge Abstract Database and the National Ambulatory Care Reporting System for duration of operating room time and ward and intensive care unit (ICU) length of stay distributions, and proportions requiring ward and ICU stays. For cancer, vascular, pediatric and percentages of surgeries, we used the Wait Times Information System for volume and attrition estimates. For cardiac, we used the CorHealth Ontario Cardiac Registry for volume and attrition estimates, and for transplant, we used Trillium's Organ and Tissue Allocation System for volume and attrition estimates. We used the Surgery Efficiency Target Program to provide the number of operating rooms by region and turnover time distributions.
Key input parameters included distributions for operating room time, ward and ICU length of stay, and estimates of the number of operating rooms and historical percentages of surgeries requiring ward and ICU stays (Table 1 ). Regional inputs are included in Appendix 1.

\section{Estimating the size of the incremental backlog}

Ontario has a population of 14.7 million and is subdivided into 5 health regions (West, Central, Toronto, East and North). ${ }^{8,9}$ In 2019/20, 90 facilities in Ontario reported 643395 surgical procedures completed in fully equipped operating rooms. ${ }^{10}$ These surgical procedures are classified into 4 priority levels (P1-P4) based on a patient's clinical condition, to standardize appropriate wait times across Ontario. ${ }^{7}$ P 1 cases are "life or limb" emergencies and the P2-P4 wait time categories have different maximum wait time targets, with more time-sensitive service areas such as cancer and cardiac surgeries having more aggressive time targets than those for other conditions. The targets associated with each priority level reflect the need to accelerate care to minimize impact on survival for patients with life-threatening disease (e.g., cancer, cardiac and vascular disease) and to accelerate care in the case of other surgical conditions (e.g., joint replacement, cataract surgery) to minimize the impact of disability on patients.

We estimated the size of the accumulated backlog from Mar. 15 to June 13, 2020, which includes gradual ramp-up activity from the Ministry of Health announcement to reopen nonemergent surgeries on May 26, 2020, up to June 13, 2020. We calculated the backlog size as the difference between the expected and the observed number of surgeries during the aforementioned time period. This backlog is incremental to the existing surgical backlog in Ontario and includes cancelled or postponed surgeries and patients unable to attend a surgical consult because of COVID-19. 
Table 1: Provincial inputs by surgery type with data source specified*

\begin{tabular}{|c|c|c|c|c|c|c|c|}
\hline $\begin{array}{l}\text { Ontario summary: } \\
\text { input table }\end{array}$ & Backlog size $\dagger$ & OR time, hr $\ddagger$ & $\begin{array}{c}\% \\
\text { to ward }\end{array}$ & $\begin{array}{c}\% \\
\text { to ICU }\end{array}$ & Ward LOS, d $\ddagger$ & ICU LOS, df & $\begin{array}{l}\text { No. } \\
\text { of ORs }\end{array}$ \\
\hline Data source & WTIS, CORC, TOTAL & DAD/NACRS & DAD & DAD & DAD & DAD & SETP \\
\hline \multicolumn{8}{|l|}{ Procedure type§ } \\
\hline Cancer P2-P3 & $1537(486-3427)$ & $2.0(1.2-3.5)$ & 54 & 10 & $3.0(1.0-5.3)$ & $1.8(1.0-3.3)$ & 818 \\
\hline Cancer P4 & 3615 (2440-4869) & $1.5(0.8-3.0)$ & 50 & 5 & $2.0(1.0-4.0)$ & $1.6(0.9-3.0)$ & 818 \\
\hline Vascular P2-P3 & $940(430-1,635)$ & $2.1(1.3-3.2)$ & 63 & 18 & $3.0(1.0-7.0)$ & $1.8(1.0-3.8)$ & 463 \\
\hline Vascular P4 & $935(412-1516)$ & $1.7(1.2-2.8)$ & 42 & 13 & $2.3(1.0-5.0)$ & $1.3(1.0-3.0)$ & 463 \\
\hline Transplant & $243(22-577)$ & $4.9(3.8-7.9)$ & 100 & 65 & $7.0(6.0-11.5)$ & $3.0(1.3-6.5)$ & 126 \\
\hline Cardiac CABG & $295(150-440)$ & $4.3(3.7-5.2)$ & 100 & 99 & $4.1(3.1-6.0)$ & $1.2(1.0-2.2)$ & 131 \\
\hline Cardiac Valve & $175(89-261)$ & $4.7(3.9-5.8)$ & 100 & 99 & $4.3(3.1-6.2)$ & $1.5(1.0-3.0)$ & 131 \\
\hline Other P2-P3 & 20400 (15 752-25 098) & $1.1(0.6-1.7)$ & 27 & 2 & $2.0(1.0-3.0)$ & $1.9(1.0-4.6)$ & 842 \\
\hline Other P4 & 107873 (95 994-119 917) & $0.8(0.3-1.5)$ & 21 & 1 & $2.0(1.0-2.0)$ & $1.1(0.9-2.7)$ & 842 \\
\hline Pediatric P2-P3 & 3151 (1431-5729) & $1.2(0.7-1.8)$ & 19 & 5 & $2.0(1.0-4.5)$ & $2.1(1.0-11.6)$ & 623 \\
\hline Pediatric P4 & $9200(7301-11$ 122) & $0.8(0.5-1.3)$ & 14 & 1 & $1.0(1.0-2.0)$ & $1.0(0.8-2.0)$ & 623 \\
\hline \multicolumn{8}{|c|}{ 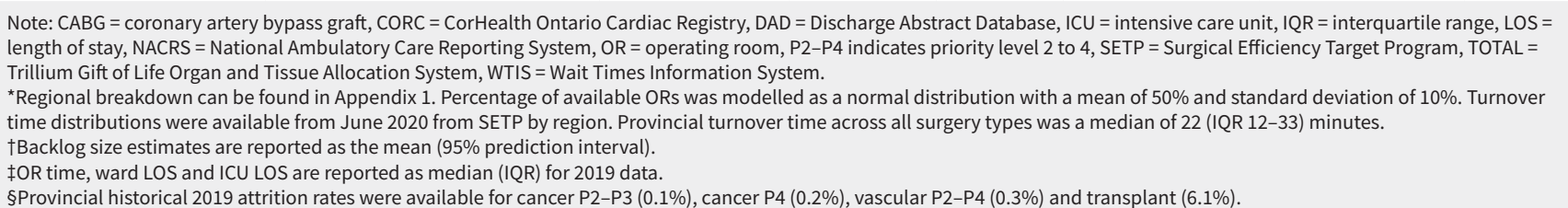 } \\
\hline
\end{tabular}

\section{Estimating the clearance time of the incremental backlog}

We estimated the clearance time by dividing the backlog size by the throughput of an operating room, an adaptation of Little's Law from queuing theory. ${ }^{11}$ To estimate the operating room throughput, we derived the operating room time distributions by surgery type and region from 2019 data. We derived the surgical turnover time distributions by region from June 2020 data, collected as part of the province's Surgery Efficiency Target Program. These data reflect an increase in historical turnover times arising from additional donning and doffing and cleaning protocols for COVID-19. ${ }^{12}$ We used data from a few months into the pandemic because by that time, surgical staff would have been accustomed to the additional personal protective equipment (PPE) protocols required and these data would more accurately represent the turnover time during surge activities. We rounded down the throughput in an 8-hour day, to represent the number of full surgeries accomplished per day. To ensure that the 8-hour day is fully used, we added 1 extra patient per day per operating room whenever more than 1.5 hours remained in a day (excluding transplants).

We based the number of operating rooms on the historical number of rooms that performed each surgery type in 2019. To account for variation in ramp-up activity, we assumed the distribution of the percentage of available operating rooms participating in the surge to be normal, with a mean of $50 \%$ and standard deviation of $10 \%$. For example, if a hospital had 4 operating rooms during a regular day and the percentage available was $50 \%$, we assumed 2 operating rooms would be active per surge day.
We combined backlog estimates with operating room throughputs and available operating rooms to calculate the clearance time for each region, summing across all surgery types. We did not consider clinical prioritization of patients; we processed each surgery type serially, implying hospitals would allocate the surge time to only 1 type of surgery at a time. Although this may not reflect actual prioritization approaches taken by an individual hospital, this simplified modelling approach is valid for the primary intent of the study, which was to estimate total clearance time. The provincial clearance time is the volumeweighted average of the clearance time in each region. As a point of comparison, we also calculate the clearance time for timesensitive surgeries only, assuming these surgeries are prioritized and assigned the surge time exclusively over elective procedures.

\section{Estimating the resources required to clear the backlog}

The key resources required to clear the backlog are operating room time, ward beds and ICU beds. We estimated weekly operating room time using the operating room throughput and the historical surgery duration distributions by surgery type and region in 2019. We estimated weekly ward and ICU bed requirements by surgery type and region using the operating room throughput, proportion to ward or ICU and the associated length of stay distributions. We calculated provincial estimates as a volume-weighted average among regions. For living donor transplant volumes, we considered ward beds for the donor and recipient. We did not cap the weekly ward and ICU bed requirements. These numbers are intended as additional information to be used with regional bed capacity reports to assess the feasibility of the surge scenario. 


\section{Statistical analysis}

We forecasted the expected number of surgeries using time series forecasting models by region and by surgery type. We trained the forecasts on historical weekly data from January 2017 to October 2019 and validated them on data from October 2019 to Mar. 8, 2020. The modelling options included seasonal naïve for observed weekly volumes less than 50 , seasonal and trend decomposition using locally estimated scatterplot smoothing (LOESS), dynamic harmonic regression with trigonometric terms for seasonality, and TBATS state space models. ${ }^{13-16}$ For deceased and living donor-related transplants, we assumed that donor volumes were available to process the transplant backlog. For each surgical category (except for cardiac), we selected the model with the best performance during the validation period (minimum root

\section{A) Cancer P2-P4}

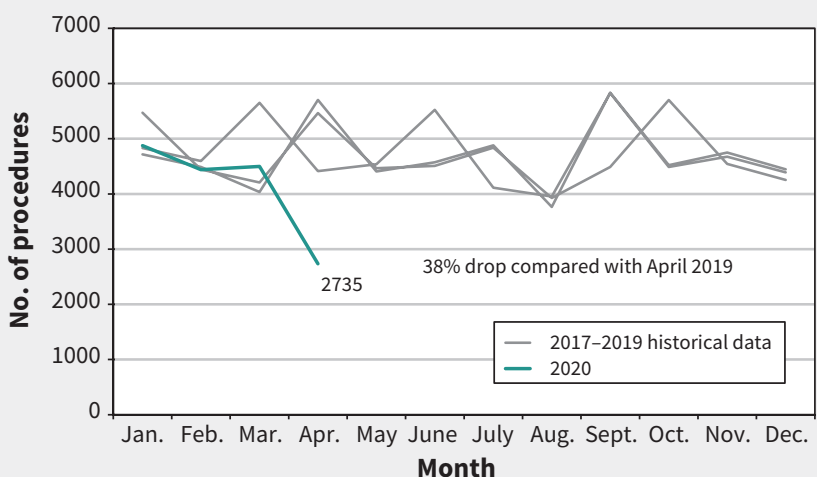

\section{C) Vascular P2-P4}

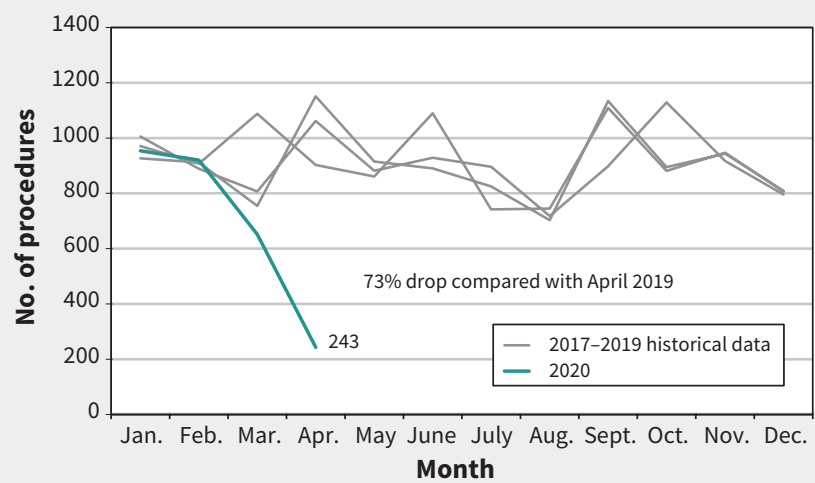

\section{E) Transplant}

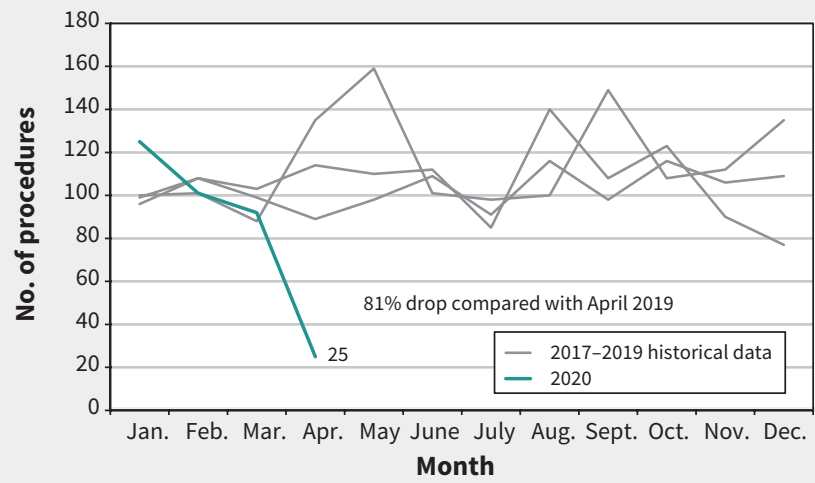

B) Other P2-P4 (excluding cardiac, transplant, pediatric and vascular)

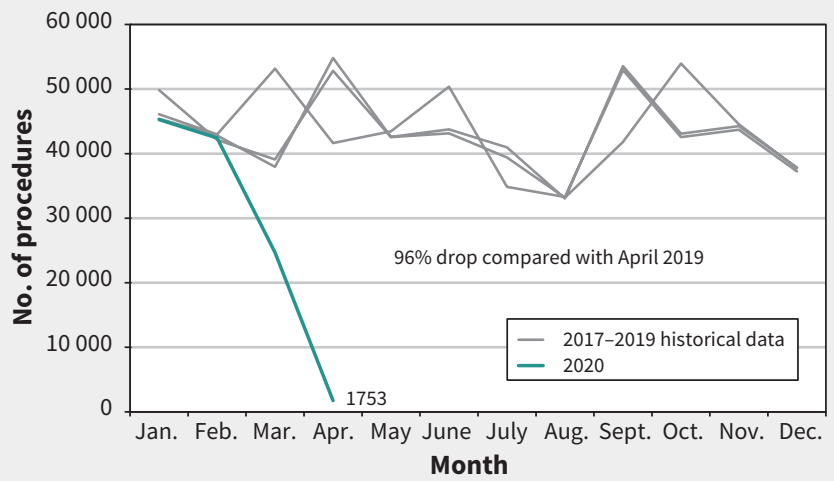

D) Pediatric P2-P4

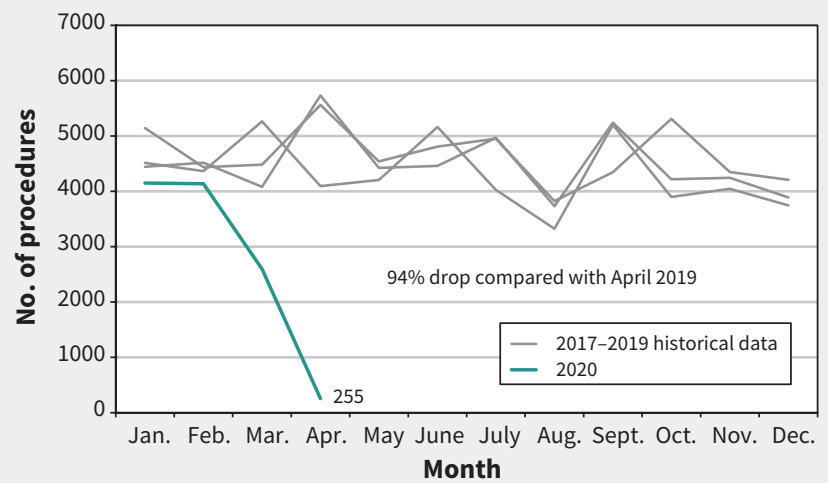

F) Cardiac (coronary artery bypass graft and valve)

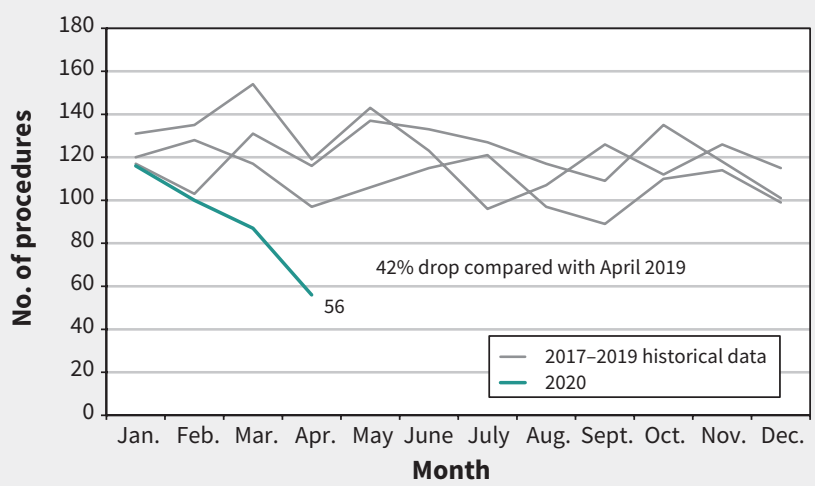

Figure 2: Monthly volume trends for surgical procedures in Ontario from 2017 to 2020 (up to and including April 2020) including oncology, vascular, cardiac, transplant and other surgeries. Report date: May 20, 2020. Data source: Wait Times Information System, Ontario Health (Cancer Care Ontario); Trillium Gift of Life Network Organ and Tissue Allocation System, Ontario Health - Trillium Gift of Life Network; CorHealth Ontario Cardiac Registry. Note: Data are from calendar years 2017 to 2020, inclusive of April 2020; P2-P4 indicates priority level 2 to 4 . The grey lines represent monthly volume trends from 2017 to 2019 and the blue line represents the monthly trends for 2020 up to April 2020. CABG = coronary artery bypass graft. 
mean squared error). ${ }^{15}$ We used a similar method to calculate expected cardiac procedures based on historical trends in the CorHealth Ontario Registry. ${ }^{17}$ To account for the variability and uncertainty in the inputs, we conducted probabilistic sensitivity analysis. The probabilistic sensitivity analysis used 1000 trials, and we calculated the mean for each output of the model along with 95\% confidence intervals (Cls). Additional details (forecasting methods and model selection) are included in Appendix 1.

\section{5\% prediction interval ....... Mean forecast _ $\quad$ Actual}

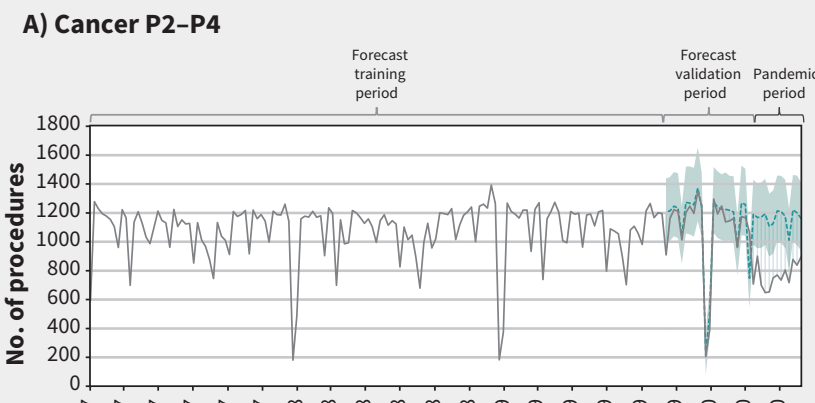

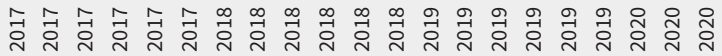

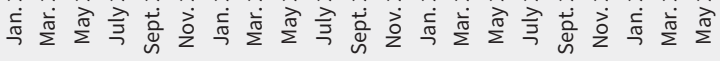
Week

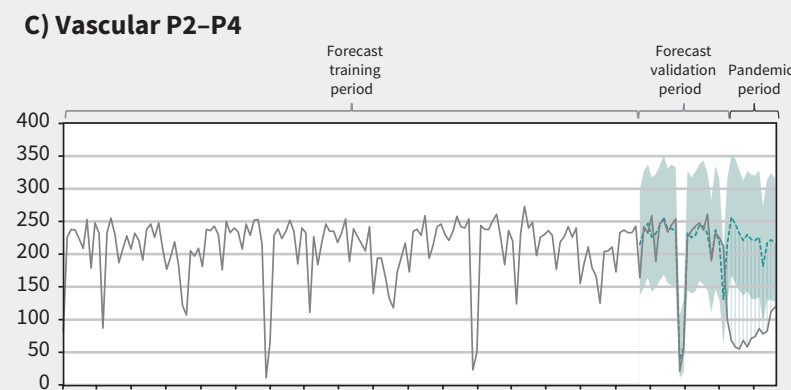

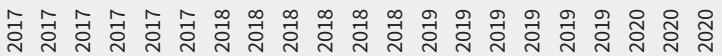

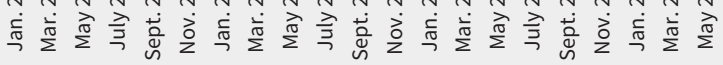
Week

\section{B) Other P2-P4}

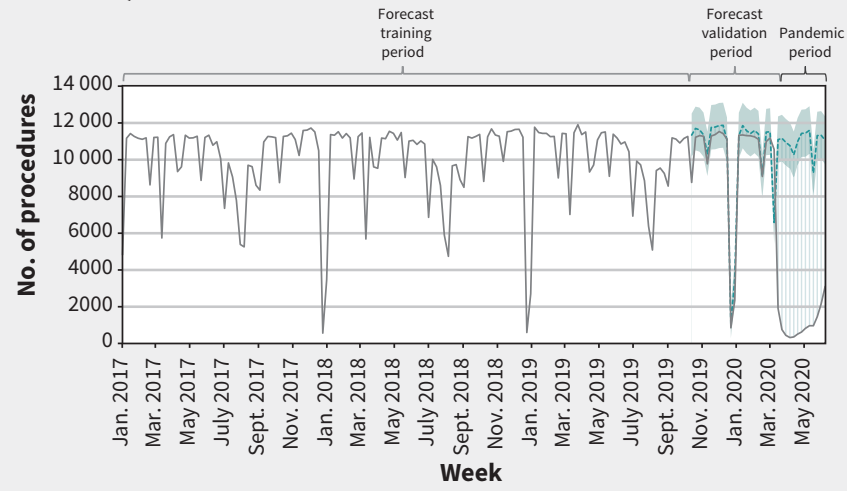

\section{D) Pediatric P2-P4}

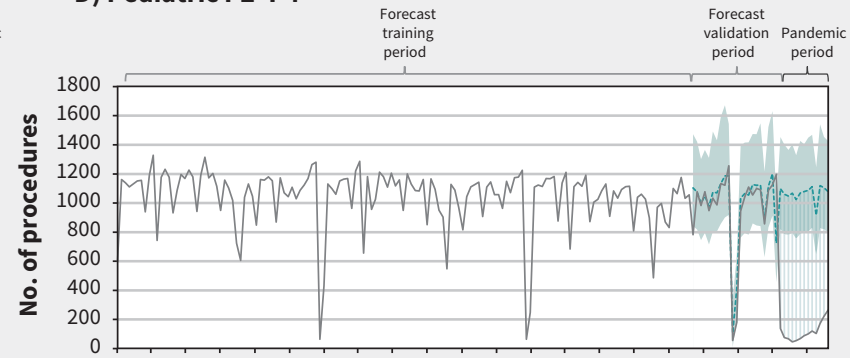

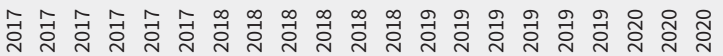

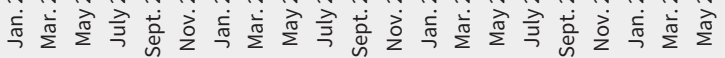
Week

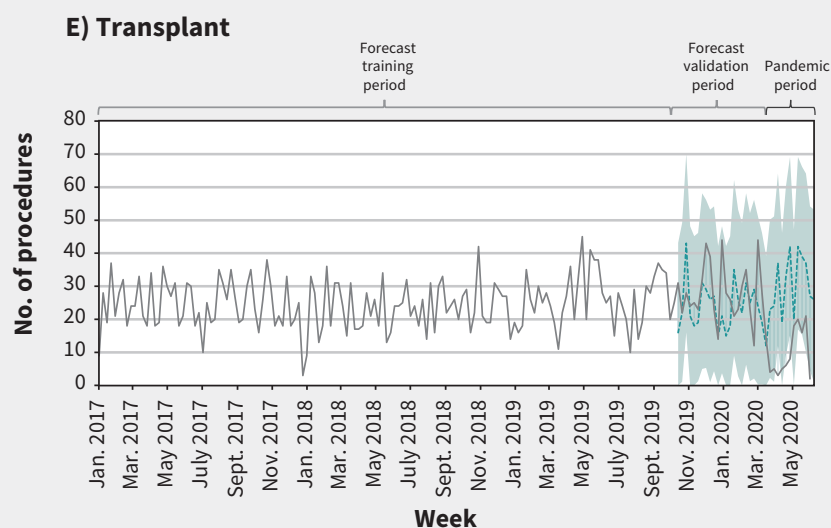

Figure 3: Weekly volumes versus forecasts for surgical procedures in Ontario from 2017 to 2020 (up to and including June 13, 2020) including cancer, vascular, pediatric, transplant and other surgeries. Report date: June 23, 2020. Data source: Wait Times Information System, Ontario Health (Cancer Care Ontario). Note: Data are from calendar year 2017 to 2020, inclusive of June 13, 2020; P2-P4 indicates priority level 2 to 4. 


\section{Ethics approval}

Ontario Health (Cancer Care Ontario) is designated a "prescribed entity" for the purposes of section 45(1) of the Personal Health Information Protection Act of 2004. As a prescribed entity, Ontario Health (Cancer Care Ontario) is authorized to collect personal health information from health information custodians without the consent of the patient, and to use such personal health information for the purpose of analysis or compiling statistical information with respect to the management, evaluation or monitoring of the allocation of resources to or planning for all or part of the health system, including the delivery of services. Trillium Gift of Life Network is governed by the Trillium Gift of Life Network Act of 1990, where section 8.8 specifies that one of the objects of Trillium Gift of Life Network is to collect, analyze and publish information relating to the donation and use of tissue. The cardiac clinical registry data used in this publication are from participating hospitals through CorHealth Ontario, which serves as an advisory body to the Ontario Ministry of Health and Long-Term Care (MOHLTC), is funded by the MOHLTC and is dedicated to improving the quality, efficiency, access and equity in the delivery of the continuum of adult cardiovascular, vascular and stroke services in Ontario, Canada. Because this study is in compliance with privacy regulations, ethics review was not required.

\section{Results}

In April 2020, there were 38\% fewer cancer surgeries, 42\% fewer cardiac surgeries, $73 \%$ fewer vascular surgeries, $81 \%$ fewer transplant surgeries, $94 \%$ fewer pediatric surgeries and $96 \%$ fewer other adult surgeries compared with April 2019 (Figure 2). Between Mar. 15 and June 13, 2020, the incremental provincial backlog was 148364 surgeries (95\% prediction interval $124508-$ 174589). Weekly time series forecasts are shown in Figure 3; weekly accumulation of the provincial mean backlog is illustrated in Figure 4, with an average provincial increase of 11413 surgeries per week.

The provincial median turnover time across all surgery types from March to June 2020 was 21 minutes (interquartile range [IQR] 11-32), a 31\% increase compared with March to June 2019 ( $p=0.3$, Mood's median test). The provincial median turnover times from April to June 2020 were April, 29 minutes (IQR 18-41); May, 25 minutes (IQR 15-37); and June, 22 minutes (IQR 12-33). The provincial operating room throughput during the clearance period was 717 patients per week ( $95 \% \mathrm{Cl} 326-1368)$. For all surgery types, it will take about 84 weeks $(95 \% \mathrm{Cl} 46-145)$ to clear the backlog. For time-sensitive surgeries only, it will take about 14 weeks $(95 \% \mathrm{Cl} 8-23)$ to clear the backlog, assuming all surge resources are dedicated to time-sensitive surgeries only.

The provincial average weekly resources required to clear all surgery types in the backlog are 719 operating room hours (95\% Cl 431-1038), 265 ward beds (95\% Cl 87-678) and 9 ICU beds (95\% Cl 4-20). The weekly resource requirements are crucial to ensure that hospitals select a sustainable surge scenario based on local resources available. Provincial and regional estimates of the backlog size by surgery type, clearance times and resources required to clear the backlog are shown in Table 2. Provincial results from the probabilistic sensitivity analysis showing the variability in the outputs are summarized in Figure 5.

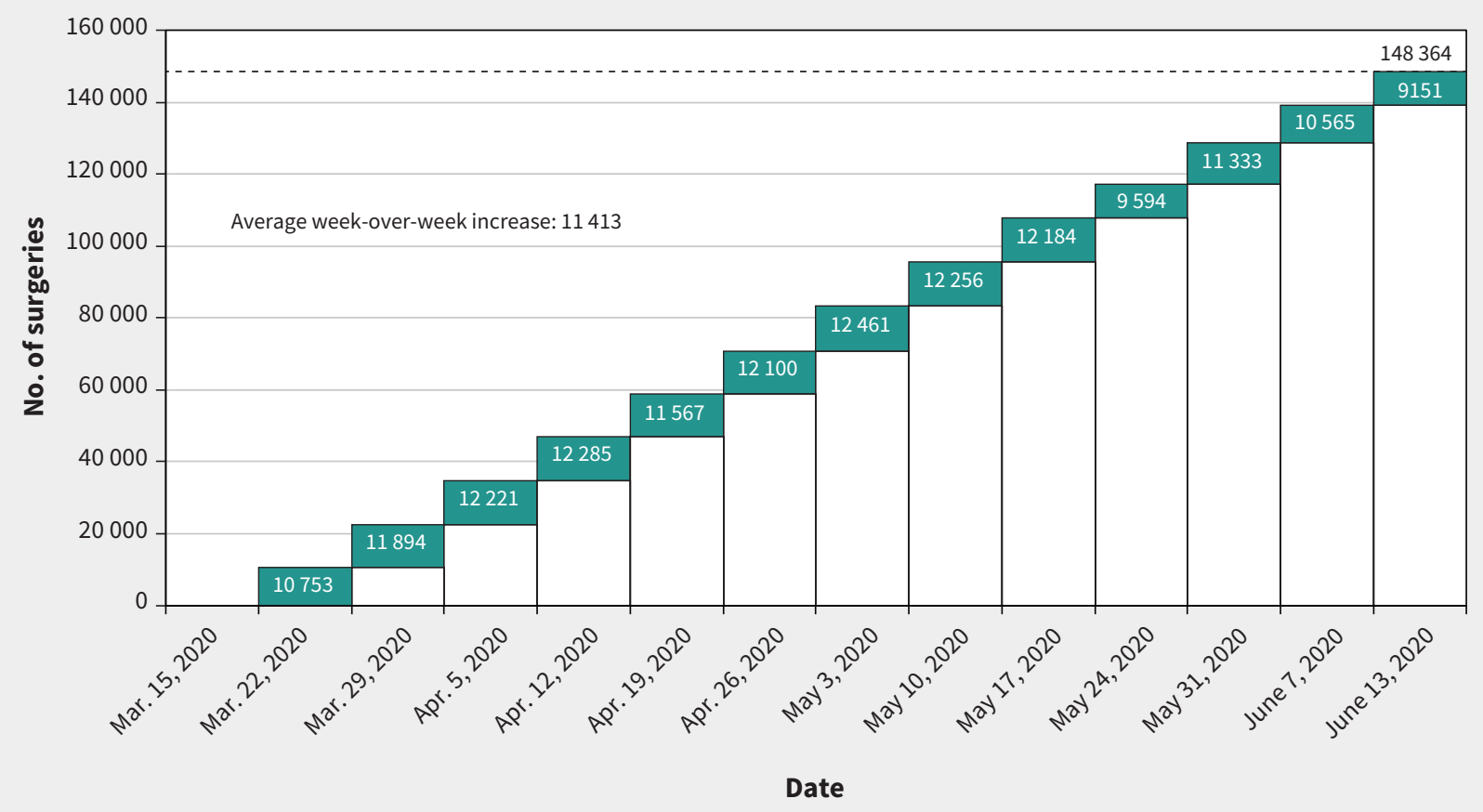

Figure 4: Week-over-week accumulation of the mean provincial backlog for all surgery types from Mar. 15, 2020, to June 13, 2020, for a total mean backlog size of 148364 surgeries. 


\section{Interpretation}

Our analyses quantify the impact of COVID-19 on surgeries in Ontario. The wide $\mathrm{Cls}$ (11 mo to $2.8 \mathrm{yr}$ ) on the clearance time estimates indicate the uncertainty and variation inherent in the analysis. Clearance times depend on the extent of surgical recov- ery and if a surge in surgical activity is undertaken. The results reflect a gradual recovery in surgical activity from the Ministry of Health announcement to reopen nonemergent surgeries on May 26,2020 , up to June 13,2020 . Without any increases in resources to support surge activity, incoming new cases will lead to a subsequent backlog.

Table 2: Provincial and regional results from the probabilistic sensitivity analysis showing the estimated backlog size and the time and resources required to clear the backlog

\begin{tabular}{|c|c|c|c|c|c|c|}
\hline \multirow[b]{2}{*}{ Category or outcome } & \multicolumn{6}{|c|}{ Health region } \\
\hline & Ontario* & West & Central & Toronto & East & North \\
\hline \multicolumn{7}{|c|}{ Estimated backlog size by surgical category $\dagger$} \\
\hline Cancer P2-P3 & $\begin{array}{c}1537 \\
(486-3427)\end{array}$ & $\begin{array}{c}206 \\
(75-552)\end{array}$ & $\begin{array}{c}308 \\
(130-588)\end{array}$ & $\begin{array}{c}488 \\
(126-1265)\end{array}$ & $\begin{array}{c}376 \\
(106-714)\end{array}$ & $\begin{array}{c}159 \\
(49-308)\end{array}$ \\
\hline Cancer P4 & $\begin{array}{c}3615 \\
(2440-4869)\end{array}$ & $\begin{array}{c}927 \\
(597-1259)\end{array}$ & $\begin{array}{c}700 \\
(450-952)\end{array}$ & $\begin{array}{c}986 \\
(698-1298)\end{array}$ & $\begin{array}{c}911 \\
(675-1148)\end{array}$ & $\begin{array}{c}91 \\
(19-212)\end{array}$ \\
\hline Vascular P2-P3 & $\begin{array}{c}940 \\
(430-1635)\end{array}$ & $\begin{array}{c}202 \\
(60-408)\end{array}$ & $\begin{array}{c}296 \\
(154-502)\end{array}$ & $\begin{array}{c}97 \\
(31-176)\end{array}$ & $\begin{array}{c}284 \\
(166-405)\end{array}$ & $\begin{array}{c}61 \\
(20-145)\end{array}$ \\
\hline Vascular P4 & $\begin{array}{c}935 \\
(412-1516)\end{array}$ & $\begin{array}{c}369 \\
(160-587)\end{array}$ & $\begin{array}{c}314 \\
(179-451)\end{array}$ & $\begin{array}{c}128 \\
(54-209)\end{array}$ & $\begin{array}{c}111 \\
(18-223)\end{array}$ & $\begin{array}{c}13 \\
(1-46)\end{array}$ \\
\hline Transplant & $\begin{array}{c}243 \\
(22-577)\end{array}$ & $\begin{array}{c}48 \\
(4-113)\end{array}$ & NA & $\begin{array}{c}124 \\
(11-293)\end{array}$ & $\begin{array}{c}72 \\
(7-170)\end{array}$ & NA \\
\hline Cardiac CABG & $\begin{array}{c}295 \\
(150-440)\end{array}$ & $\begin{array}{c}77 \\
(39-115)\end{array}$ & $\begin{array}{c}71 \\
(36-106)\end{array}$ & $\begin{array}{c}86 \\
(44-128)\end{array}$ & $\begin{array}{c}37 \\
(19-55)\end{array}$ & $\begin{array}{c}23 \\
(12-35)\end{array}$ \\
\hline Cardiac Valve & $\begin{array}{c}175 \\
(89-261)\end{array}$ & $\begin{array}{c}29 \\
(15-43)\end{array}$ & $\begin{array}{c}64 \\
(33-95)\end{array}$ & $\begin{array}{c}51 \\
(26-76)\end{array}$ & $\begin{array}{c}20 \\
(10-30)\end{array}$ & $\begin{array}{c}12 \\
(6-17)\end{array}$ \\
\hline Other P2-P3 & $\begin{array}{c}20400 \\
(15752-25098)\end{array}$ & $\begin{array}{c}5361 \\
(3418-7305)\end{array}$ & $\begin{array}{c}5858 \\
(5082-6633)\end{array}$ & $\begin{array}{c}2098 \\
(1458-2737)\end{array}$ & $\begin{array}{c}5671 \\
(4779-6613)\end{array}$ & $\begin{array}{c}1412 \\
(1013-1811)\end{array}$ \\
\hline Other P4 & $\begin{array}{c}107873 \\
(95994-119917)\end{array}$ & $\begin{array}{c}34660 \\
(31117-38203)\end{array}$ & $\begin{array}{c}26560 \\
(23580-29705)\end{array}$ & $\begin{array}{c}13102 \\
(11674-14530)\end{array}$ & $\begin{array}{c}26702 \\
(24097-29307)\end{array}$ & $\begin{array}{c}6849 \\
(5526-8171)\end{array}$ \\
\hline Pediatric P2-P3 & $\begin{array}{c}3151 \\
(1431-5729)\end{array}$ & $\begin{array}{c}858 \\
(179-1537)\end{array}$ & $\begin{array}{c}561 \\
(401-750)\end{array}$ & $\begin{array}{c}624 \\
(379-870)\end{array}$ & $\begin{array}{c}869 \\
(431-2123)\end{array}$ & $\begin{array}{c}239 \\
(42-449)\end{array}$ \\
\hline Pediatric P4 & $\begin{array}{c}9200 \\
(7301-11122)\end{array}$ & $\begin{array}{c}3004 \\
(2479-3501)\end{array}$ & $\begin{array}{c}2513 \\
(2128-2899)\end{array}$ & $\begin{array}{c}1311 \\
(1003-1618)\end{array}$ & $\begin{array}{c}1831 \\
(1375-2339)\end{array}$ & $\begin{array}{c}540 \\
(317-764)\end{array}$ \\
\hline $\begin{array}{l}\text { Total estimated } \\
\text { backlog size }\end{array}$ & $\begin{array}{c}148364 \\
(124508-174589)\end{array}$ & $\begin{array}{c}45742 \\
(38143-53624)\end{array}$ & $\begin{array}{c}37245 \\
(32173-42680)\end{array}$ & $\begin{array}{c}19093 \\
(15504-23199)\end{array}$ & $\begin{array}{c}36885 \\
(31683-43127)\end{array}$ & $\begin{array}{c}9399 \\
(7005-11959)\end{array}$ \\
\hline \multicolumn{7}{|c|}{ Estimated time to clear the backlog $\ddagger$} \\
\hline $\begin{array}{l}\text { Estimated } \\
\text { throughput } \\
\text { (patients per week) }\end{array}$ & $\begin{array}{c}717 \\
(326-1367)\end{array}$ & $\begin{array}{c}933 \\
(328-2532)\end{array}$ & $\begin{array}{c}809 \\
(264-2250)\end{array}$ & $\begin{array}{c}278 \\
(108-642)\end{array}$ & $\begin{array}{c}710 \\
(240-1736)\end{array}$ & $\begin{array}{c}278 \\
(92-669)\end{array}$ \\
\hline $\begin{array}{l}\text { Estimated clearance } \\
\text { time, wk }\end{array}$ & $\begin{array}{c}84 \\
(46-145)\end{array}$ & $\begin{array}{c}79 \\
(31-159)\end{array}$ & $\begin{array}{c}74 \\
(26-156)\end{array}$ & $\begin{array}{c}120 \\
(58-231)\end{array}$ & $\begin{array}{c}87 \\
(34-180)\end{array}$ & $\begin{array}{c}53 \\
(20-117)\end{array}$ \\
\hline \multicolumn{7}{|c|}{ Estimated resources required $\ddagger$} \\
\hline OR time (h) per week & $\begin{array}{c}719 \\
(431-1038)\end{array}$ & $\begin{array}{c}926 \\
(552-1344)\end{array}$ & $\begin{array}{c}735 \\
(433-1057)\end{array}$ & $\begin{array}{c}452 \\
(260-658)\end{array}$ & $\begin{array}{c}705 \\
(420-1022)\end{array}$ & $\begin{array}{c}271 \\
(163-388)\end{array}$ \\
\hline Ward beds per week & $\begin{array}{c}265 \\
(87-678)\end{array}$ & $\begin{array}{c}352 \\
(58-1483)\end{array}$ & $\begin{array}{c}295 \\
(48-1142)\end{array}$ & $\begin{array}{c}99 \\
(22-305)\end{array}$ & $\begin{array}{c}258 \\
(44-935)\end{array}$ & $\begin{array}{c}110 \\
(15-392)\end{array}$ \\
\hline ICU beds per week & $\begin{array}{c}9 \\
(4-20)\end{array}$ & $\begin{array}{c}14 \\
(3-44)\end{array}$ & $\begin{array}{c}5 \\
(1-17)\end{array}$ & $\begin{array}{c}9 \\
(2-27)\end{array}$ & $\begin{array}{c}7 \\
(2-20)\end{array}$ & $\begin{array}{c}3 \\
(1-10)\end{array}$ \\
\hline
\end{tabular}




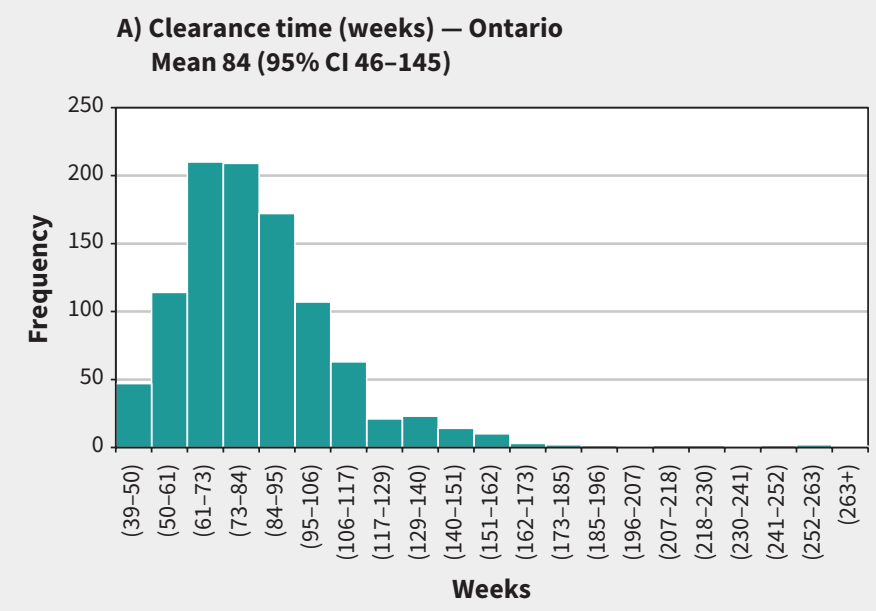

B) OR time (h) per week - Ontario Mean 719 (95\% Cl 431-1038)

C) Patients per week - Ontario Mean 717 (95\% Cl 326-1367)

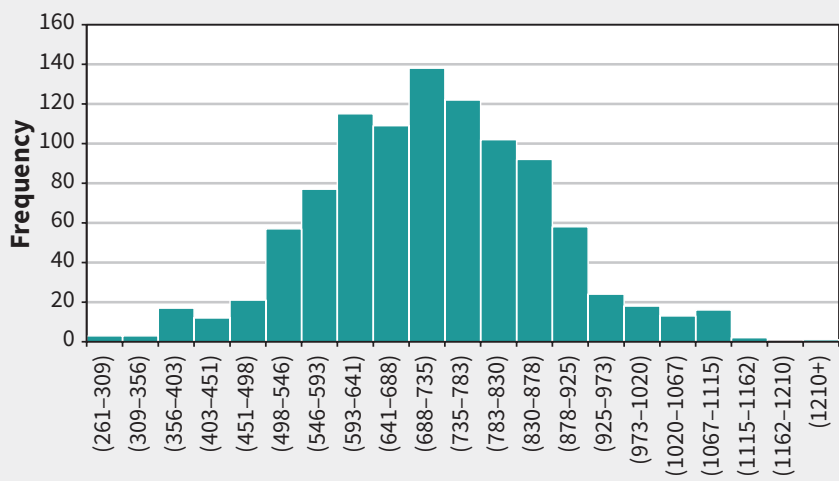

OR hours per week

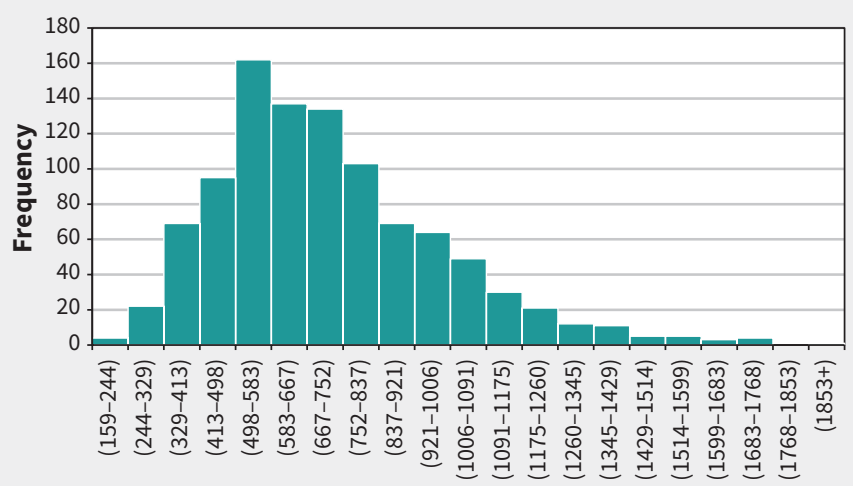

Patients per week

D) Ward beds per week - Ontario

Mean 265 (95\% Cl 87-678)

E) ICU beds per week - Ontario
Mean $9(95 \% \mathrm{CI} 4-20)$

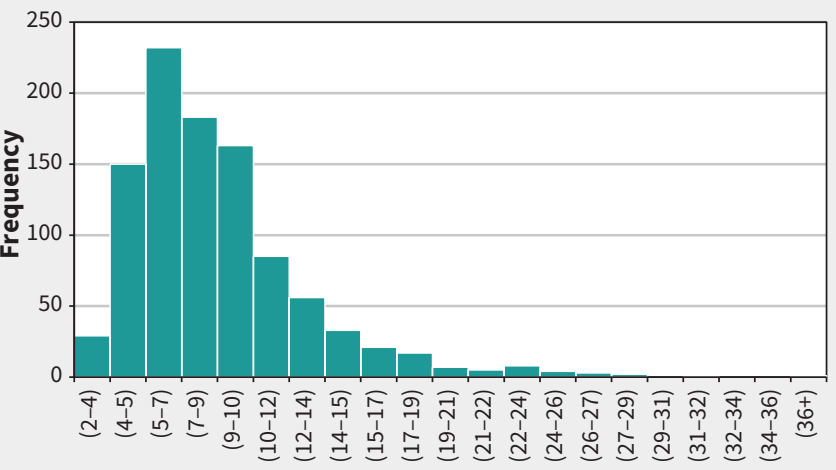

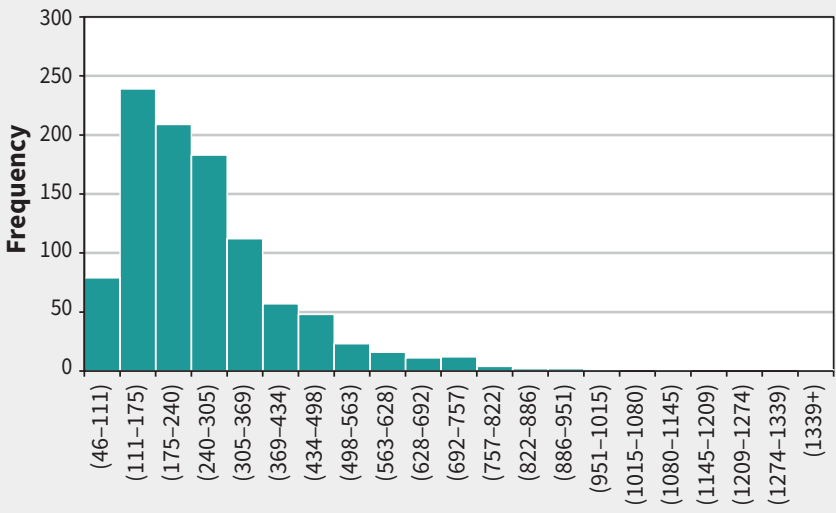

Ward beds per week

\section{ICU beds per week}

Figure 5: Provincial results from the probabilistic sensitivity analysis for (A) clearance time, (B) operating room (OR) time per week, (C) patients per week, (D) ward beds per week and (E) intensive care unit (ICU) beds per week. The analyses were run 1000 times, and the frequencies add up to 1000 . Note: $\mathrm{Cl}=$ confidence interval. 
Our framework for modelling the surgical backlog can be adapted to other jurisdictions, using local data to assist with recovery planning. We have created a deterministic, Excel-based tool using average inputs to help regional partners plan for restarting surgeries (see the Excel tool, available at https:// github.com/wangjona/surgicalbacklog). According to Ontario Health recommendations, hospitals must ensure they can achieve at least $10 \%$ acute bed occupancy within 48 hours and have a minimum of 15 days of PPE onsite, coupled with a 30-day alternative backstop in each region or subregion. ${ }^{18}$ Hospital planners can use estimates of their upcoming surgery volumes in conjunction with the tool to assess the feasibility of the recommended criteria.

\section{Limitations}

Our analysis does not account for the potential occurrence of future waves of COVID-19 in Ontario. A delayed recovery or ramping down of nonemergent surgeries after a subsequent COVID-19 wave will continue to cause the backlog to grow, increasing the clearance time and resource estimates.

We considered clearance time estimates serially with operating room time distributions. Including multiple categories of surgeries in 1 operating room day (e.g., scheduling cancer and vascular surgeries within the same operating room day) with stochastic operating room times may reduce the clearance time and resources required. Further research on optimal priority scheduling of patients to improve operating room use in pandemic recovery should be a next step.

Modelling assumes availability of health human resources, beds, drugs and PPE. However, the pandemic has caused significant challenges related to health human resources in many jurisdictions, including Ontario, as operating room staff have been reallocated to other hospital departments and may be experiencing work fatigue. ${ }^{19-25}$ Regions are also coping with a reduction in beds resulting from the movement of patients from long-term care into hospitals, coupled with a reduction of beds per room to accommodate physical distancing protocols. ${ }^{26}$ Therefore, it may be difficult to ensure adequate staffing and beds to support ramp-up plans. ${ }^{19}$ Similarly, drug and PPE shortages resulting from supply chain disruptions have been identified as a challenge in restarting surgeries. ${ }^{27,28}$ Provincial supply chains must be robust to secure sufficient drugs and PPE. Modelling requirements and supply for health human resources, beds, critical medications and PPE would be beneficial future steps.

Finally, we used historical data to forecast the expected surgical volumes and to estimate resource utilization patterns. The expected surgical volumes are based on historical patterns, which may change in the pandemic recovery phase. There is a paucity of data informing assumptions on the demand for surgeries during the recovery phase and the potential ramp-down phase during subsequent COVID-19 waves. We also assumed that all forecasted surgical volumes are appropriately indicated for surgery, which may not be true in all cases..$^{29}$ For resource utilization patterns, patients waiting longer for treatment may have higher resource utilization than those receiving care before the pandemic, owing to disease progression as one might see in cancer or cardiac care, or may become ineligible for surgery as their condition progresses. In addition, patients waiting for transplants may lose opportunities for organ donation. Consequently, this analysis should be considered with other guidance tools, such as ethical frameworks and clinical prioritization guides. ${ }^{30}$ Without significant increases in resources, prioritization of patients for surgery based on survival and quality-of-life outcomes is paramount.

\section{Conclusion}

We presented an approach to modelling the incremental provincial and regional surgical backlog in Ontario and the time and resources required to clear the backlog as a result of COVID-19. This work shows the unprecedented magnitude of the secondary impact of COVID-19 on surgical care in Ontario. Our framework for modelling the surgical backlog can be adapted to other jurisdictions using local data to assist with recovery planning. To effectively manage this impact on more than 140000 patients, health systems and surgical leaders cannot get back to business as usual, but rather must employ innovative system-based solutions to provide patients with timely surgical care and prepare for future COVID-19 waves. $^{31-33}$

\section{References}

1. WHO timeline - COVID-19 [statement]. Geneva: World Health Organization; updated 2020 July 30. Available: www.who.int/news-room/detail/27-04-2020 -who-timeline-covid-19 (accessed 2020 June 14)

2. Rosenbaum L. The untold toll - the pandemic's effects on patients without COVID-19. N Engl J Med 2020;382:2368-71.

3. COVIDSurg Collaborative. Elective surgery cancellations due to the COVID-19 pandemic: global predictive modelling to inform surgical recovery plans. $\mathrm{Br} \mathrm{J}$ Surg 2020 May 12 [Epub ahead of print]. doi: 10.1002/bjs.11746.

4. Jain A, Jain P, Aggarwal S. SARS-CoV-2 impact on elective orthopaedic surgery: implications for post-pandemic recovery. J Bone Joint Surg Am 2020 May 12. [Epub ahead of print]. doi: 10.2106/JBJS.20.00602.

5. Ramping down elective surgeries and other non-emergent activities [memorandum to Ontario Health and hospitals]. Toronto: Ministry of Health and Long-Term Care; 2020 Mar. 15. Available: www.health.gov.on.ca/en/pro/ programs/publichealth/coronavirus/docs/memos/DM_OH_CMOH_memo_ COVID19_elective_surgery_March_15_2020.pdf (accessed 2020 Aug. 24).

6. COVID-19 directive \#2 for health care providers (regulated health professionals or persons who operate a group practice of regulated health professionals), issued under Section 77.7 of the Health Protection and Promotion Act (HPPA), R.S.O. 1990, C. H.7. Toronto: Ministry of Health and Long-Term Care; 2020. Available: www.health.gov.on.ca/en/pro/programs/publichealth/coronavirus/ docs/directives/RHPA_professionals.pdf (accessed 2020 Aug. 24).

7. Measuring wait times for other surgeries and procedures. Toronto: Health Quality Ontario. Available: www.hqontario.ca/System-Performance/Measuring -System-Performance/Measuring-Wait-Times-for-Other-Surgeries-and-Procedures (accessed 2020 June 11).

8. Ontario taking next steps to integrate health care system: changes will protect uninterrupted access to patient care [news release]. Toronto: Ministry of Health and Long-Term Care; 2019 Nov. 13. Available: https://news.ontario.ca/ mohltc/en/2019/11/ontario-taking-next-steps-to-integrate-health-care-system. html (accessed 2020 June 14).

9. Population estimates, quarterly [Table: 17-10-0009-01 (formerly CANSIM 051-0005)] Ottawa: Statistics Canada; 2020. Available: https://www150.statcan.gc.ca/t1/tbl1/ en/tv.action?pid=1710000901 (accessed 2020 June 17).

10. Cancer Care Ontario's data book - 2020-2021. Toronto: Ontario Health (Cancer Care Ontario); 2019. Available: https://ext.cancercare.on.ca/ext/databook/ db2021/databook.htm (accessed 2020 Aug. 24).

11. Little JDC. A proof for the queuing formula: $L=\lambda$ W. Oper Res 1961;9:383-7. doi: 10.1287/opre.9.3.383. 
12. Coccolini F, Perrone G, Chiarugi M, et al. Surgery in COVID-19 patients: operational directives. World J Emerg Surg 2020;15:25.

13. Hyndman R, Athanasopoulos G, Bergmeir C, et al. Forecast: forecasting functions for time series and linear models. R package 8.12. 2020. Available: https://pkg.robjhyndman.com/forecast/ (accessed 2020 June 17).

14. de Livera AM, Hyndman RJ, Snyder RD. Forecasting time series with complex seasonal patterns using exponential smoothing. J Am Stat Assoc 2011;106:1513-27. doi: 10.1198/jasa.2011.tm09771.

15. Hyndman RJ, Athanasopoulos G. Forecasting: principles and practice. Melbourne (AU): OTexts; 2018. Available: https://otexts.com/fpp2/ (accessed 2020 June 22).

16. Cleveland RB, Cleveland WS, McRae JE, et al. STL: a seasonal-trend decomposition procedure based on loess. J Off Stat 1990;6:3-73. Available: www.nniiem.ru/file/ news/2016/stl-statistical-model.pdf (accessed 2020 Aug. 24).

17. Tam DY, Naimark D, Natarajan MK, et al. The use of decision modelling to inform timely policy decisions on cardiac resource capacity during the COVID-19 pandemic. Can J Cardiol 2020;36:1308-12.

18. A measured approach to planning for surgeries and procedures during the COVID-19 pandemic. Toronto: Ontario Health; updated 2020 June 15. Available: www.ontariohealth.ca/sites/ontariohealth/files/2020-06/A Measured Approach to Planning for Surgeries and Procedures During the COVID-19 Pandemic.pdf (accessed 2020 Aug. 24)

19. Shoukat A, Wells CR, Langley JM, et al. Projecting demand for critical care beds during COVID-19 outbreaks in Canada. CMAJ 2020;192:E489-96.

20. Kim T. Improving preparedness for and response to coronavirus disease 19 (COVID-19) in long-term care hospitals in the Korea Tark Kim Seongnam, Korea. Infect Chemother 2020;52:133-41.

21. Chersich MF, Gray G, Fairlie L, et al. COVID-19 in Africa: care and protection for frontline healthcare workers. Global Health 2020;16:46.

22. Carenzo L, Costantini E, Greco M, et al. Hospital surge capacity in a tertiary emergency referral centre during the COVID-19 outbreak in Italy. Anaesthesia 2020;75:928-34.

23. Moghadas SM, Shoukat A, Fitzpatrick MC, et al. Projecting hospital utilization during the COVID-19 outbreaks in the United States. Proc Natl Acad Sci U S A 2020;117:9122-6.
24. Rubin R, Abbasi J, Voelker R. Latin America and its global partners toil to procure medical supplies as COVID-19 pushes the region to its limit. JAMA 2020 June 12 [Epub ahead of print]. doi: 10.1001/jama.2020.11182.

25. Sasangohar F, Jones SL, Masud FN, et al. Provider burnout and fatigue during the COVID-19 pandemic: lessons learned from a high-volume intensive care unit. Anesth Analg 2020;131:106-11.

26. Utilization of multi-bed ward rooms and inpatient placement in hospitals during COVID-19. Toronto: Ontario Health; 2020. Available: www.ontariohealth.ca/ sites/ontariohealth/files/2020-06/Utilization\%20of\%20Multi-Bed\%20Ward\%20 Rooms\%20and\%20Inpatient\%20Placement\%20in\%20Hospitals\%20During\%20 COVID-19.pdf (accessed 2020 June 22).

27. Badreldin HA, Atallah B. Global drug shortages due to COVID-19: impact on patient care and mitigation strategies. Res Soc Adm Pharm 2020 May 19 [Epub ahead of print]. doi: 10.1016/j.sapharm.2020.05.017.

28. Ranney ML, Griffeth V, Jha AK. Critical supply shortages - the need for ventilators and personal protective equipment during the COVID-19 pandemic. $N$ Engl J Med 2020;382:e41.

29. Cooper Z, Sayal P, Abbett SK, et al. A conceptual framework for appropriateness in surgical care: reviewing past approaches and looking ahead to patientcentered shared decision making. Anesthesiology 2015;123:1450-4.

30. ASCCP interim guidance for timing of diagnostic and treatment procedures for patients with abnormal cervical screening tests. Rockville (MD): American Society for Colposcopy and Cervical Pathology (ASCCP); 2020. Available: www.asccp.org/ covid-19 (accessed 2020 June 11).

31. Urbach DR, Martin D. Confronting the COVID-19 surgery crisis: time for transformational change. CMAJ 2020;192:E585-6.

32. Barron L, Kumar T. Surgical backlog must not be fixed at the expense of the healthcare system. Healthy Debate.ca 2020 Aug. 4. Available: https:// healthydebate.ca/opinions/surgical-backlog-expense (accessed 2020 Aug. 5).

33. Butler $\mathrm{C}$. How surgical smoothing could help ease the medical backlog created by COVID-19. CBC News 2020 July 13. Available: www.cbc.ca/news/canada/london/ elective-surgery-wait-times-covid-surgical-smoothing-1.5641819 (accessed 2020 Aug. 5).
Competing interests: Maria Eberg is currently an employee of IQVIA, Canada; all work performed for the submitted manuscript was done while employed at Ontario Health (Cancer Care Ontario). The work performed for the submitted manuscript is unrelated to any of her duties as an employee of IQVIA. Frances Wright reports being an employee of Ontario Health (Cancer Care Ontario), as the Skin Cancer Lead and Surgical Oncology Quality and Knowledge Transfer Lead. This article is a result of some of the work performed at Ontario Health (Cancer Care Ontario). Jonathan Irish reports receiving salary support from Ontario Health (Cancer Care Ontario) as the Provincial Head, Surgical Oncology Program. No other competing interests were declared.

This article has been peer reviewed.

Affiliations: Ontario Health (Cancer Care Ontario) (Wang, Vahid, Eberg, Milroy, Milkovich, Wright, Hunter, Zanchetta, Irish); Division of General Surgery (Wright), Sunnybrook Health Sciences Centre; Trillium Gift of Life Network (Kalladeen); Schulich Heart Centre (Wijeysundera), Sunnybrook Health Sciences Centre; Division of Cardiology (Wijeysundera), Department of Medicine and Department of Otolaryngology-Head and Neck Surgery/ Surgical Oncology (Irish), Princess Margaret
Cancer Centre/University Health Network, University of Toronto, Toronto, Ont.

Contributors: Jonathan Wang, Saba Vahid, Claudia Zanchetta and Jonathan Irish contributed to the conception and design of the work. Jonathan Wang, Saba Vahid, Maria Eberg, Shannon Milroy, Ryan Kalladeen, Frances Wright, Amber Hunter, Claudia Zanchetta, Harindra Wijeysundera and Jonathan Irish contributed to the acquisition, analysis and interpretation of data. Jonathan Wang, Saba Vahid and John Milkovich drafted the manuscript. All of the authors revised the manuscript critically for important intellectual content, gave final approval of the version to be published and agreed to be accountable for all aspects of the work.

Funding: This study was conducted with the support of Ontario Health (Cancer Care Ontario) through in-kind contributions from all authors. The Sullivan Chair in Surgical Oncology Fund/Princess Margaret Cancer Foundation supported the publication fee for this manuscript. The opinions, results, view and conclusions reported in this publication are those of the authors and do not necessarily reflect those of Ontario Health (Cancer Care Ontario) and Trillium Gift of Life Network. No endorsement by Ontario Health (Cancer Care
Ontario) and Trillium Gift of Life Network is intended or should be inferred.

Data sharing: Aggregated data for the time series modelling of surgical volume data may be requested for research purposes through the Ontario Health (Cancer Care Ontario)'s data request process immediately after publication (no end date): https://www.ccohealth. $\mathrm{ca} / \mathrm{en} /$ request-data-for-research. The data used as inputs to this modelling study (OR time, turnover time, ward and ICU length of stay, \% to ward and ICU and the number of ORs) are summarized in Appendix 1.

Acknowledgements: The authors acknowledge that a project of this scope and magnitude could not have been accomplished without the assistance and hard work of many people. Thank you to all the hard-working team members from the Access to Care Surgical Program and Analytics teams at Ontario Health (Cancer Care Ontario) as well as from the Health System Policy, Planning and Performance team at CorHealth Ontario, who all helped extract relevant data for this work.

Accepted: Aug. 17, 2020

Correspondence to: Jonathan Irish, jonathan.irish@uhn.ca 